\title{
EDITORIAL
}

\section{SUDDEN CARDIAC DEATH IN THE YOUNG: COULD EPILEPSY BE INVOLVED?}

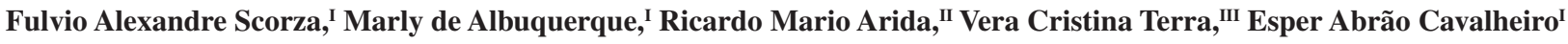

doi: $10.1590 / \mathbf{S 1 8 0 7 - 5 9 3 2 2 0 1 0 0 0 0 7 0 0 0 0 2}$

It was supposed to be a usual Thursday morning on Feb. 21, 2002, but Chris Donalty, a 21-year-old senior at a Florida college, died in his sleep. ${ }^{1}$ His girlfriend found him on his bed and immediately called the paramedics, but they were unable to revive him. ${ }^{1}$ Thus, all events leading to his death were evaluated, and an autopsy revealed no visible cause of death. ${ }^{1}$ So, what caused Chris' sudden death? He had been diagnosed with epilepsy (he suffered his first seizure in grade school at 9 years of age), but initially, his family saw no clear connection between his death and the disease for which he was being treated. ${ }^{1}$ Ultimately, physicians informed his family that Chris suffered from sudden unexplained death in epilepsy (SUDEP). ${ }^{1}$

In general terms, SUDEP is defined by precise criteria (approved in 1997 by an expert panel): a sudden, unexpected, witnessed or unwitnessed, non-traumatic and non-drowning death in patients with epilepsy, with or without evidence of a seizure and excluding documented status epilepticus, in which the postmortem examination does not reveal a toxicological or anatomical cause of death. ${ }^{2}$ Unfortunately, approximately one in a 1000 patients with chronic epilepsy will die suddenly, unexpectedly, and without explanation each year, ${ }^{3}$ and SUDEP is considered the most important, direct, epilepsy-related cause of death. ${ }^{4}$ In fact, information concerning the risk factors for SUDEP is contradictory, but potential associated factors include refractory epilepsy, the presence of generalized tonic-clonic seizures, use of antiepileptic medication (polytherapy with antiepileptic drugs), long duration of the seizure disorder,

\footnotetext{
${ }^{\text {I }}$ Disciplina de Neurologia Experimental, Universidade Federal de São Paulo (UNIFESP) - São Paulo/SP, Brasil.

II Departamento de Fisiologia, Universidade Federal de São Paulo (UNIFESP) - São Paulo/SP, Brasil.

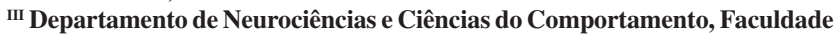
de Medicina de Ribeirão Preto, Universidade de São Paulo - Ribeirão Preto/ SP, Brasil.

Email: scorza.nexp@epm.br

Tel: $55115549-2064$
}

early onset of epilepsy, and young age. ${ }^{5,6}$ Concerning the latter, there are some issues that must be considered. In contrast to the widespread opinion that SUDEP does not occur in children, the ages of the reported cases have ranged from 8 months to 83 years. ${ }^{7}$ Although previous studies have determined different decades of peak incidence of SUDEP (i.e., third and fourth decades and second and fifth decades of life), ${ }^{7-10}$ the vast majority of reports have demonstrated that ages between 20 and 40 years are associated with the highest risk for SUDEP occurrence. ${ }^{7-10}$ In this context, understanding the mechanisms underlying SUDEP may lead to the identification of previously unrecognized risk factors that are more amenable totreatment. ${ }^{11}$ In general terms, although different disease mechanisms may play distinct roles in different patients, ${ }^{5}$ it is highly probable that the occurrence of cardiac abnormalities during and between seizures plays a role in SUDEP. ${ }^{6}$ Briefly, it is believed that a cardiovascular collapse, either from an arrhythmia due to the extreme sympathetic activation that occurs during a seizure or from hypotension induced by asystole resulting from a profound vagal activation during seizure discharge, is also possible..$^{5,6,11,12}$

Considering all of these facts (and admitting our knowledge deficit concerning the precise relationship between young age and sudden cardiac death), our research group is in complete agreement with colleagues that clarification of the risk factors and elucidation of the mechanisms responsible for SUDEP are important for the establishment of preventative measures and for determining the best strategies for seizures control. ${ }^{8}$ Meanwhile, maintaining a healthy weight, exercising regularly, consuming a healthy and balanced diet, avoiding smoking and consuming a limited amount of alcohol are other important strategies for the prevention of several chronic diseases. ${ }^{13}$ Overall, we believe that it is crucial to establish a true convergence of clinical cardiology and neurology. Thus, strategies such as taking a detailed cardiovascular 
history and determining the presence of cardiovascular disease, as well as evaluating symptoms, cardiovascular risk factors, and prior cardiac findings (electrocardiogram and echocardiogram), should be developed for patients at risk. Finally, despite some progress, SUDEP remains a significant clinical problem. Unfortunately, since the risk factors remain to be elucidated and the mechanisms of SUDEP and specific methods for its prevention remain to be stablished, prudence remains our recommendation to follow up patients with epilepsy.

\section{REFERENCES}

1. Couzin J. Epilepsy. When death strikes without warning. Science. 2008;321:31-3.

2. Nashef L. Sudden unexpected death in epilepsy: Terminology and definitions. Epilepsia. 1997;38:S6-S8.

3. Hirsch LJ, Hauser WA. Can sudden unexplained death in epilepsy be prevented? Lancet. 2004;364:2157-8.

4. Duncan JS, Sander JW, Sisodiya SM, Walker MC. Adult epilepsy. Lancet. 2006; 367:1087-100.

5. Surges R, Thijs RD, Tan HL, Sander JW. Sudden unexpected death in epilepsy: risk factors and potential pathomechanisms. Nat Rev Neurol. 2009;5:492-504.

6. Stollberger C, Finsterer J. Cardiorespiratory findings in sudden unexplained/unexpected death in epilepsy (SUDEP). Epilepsy Res. 2004;59:51-60.

7. Tomson T, Walczak T, Sillanpaa M, Sander JW. Sudden unexpected death in epilepsy: a review of incidence and risk factors. Epilepsia 2005;46:54-61.
8. Bell Gs, Sander JW. Sudden unexpected death in epilepsy. Risk factors, possible mechanisms and prevention: a reappraisal. Acta Neurol Taiwan. 2006; 15:72-83.

9. Antoniuk SA, Oliva LV, Bruck I, Malucelli M, Yabumoto S, Castellano JL. Sudden unexpected, unexplained death in epilepsy autopsied patients. Arq Neuropsiquiatr. 2001;59:40-5.

10. Terrence CF Jr, Wisotzkey HM, Perper JA. Unexpected, unexplained death in epileptic patients. Neurology. 1975;25:594-8.

11. So EL. What is known about the mechanisms underlying SUDEP? Epilepsia. 2008; 49:93-8.

12. Ryvlin P, Montavont A, Kahane P. Sudden unexpected death in epilepsy: from mechanisms to prevention. Curr Opin Neurol 2006;19:194-9.

13. He K. Fish, long-chain omega-3 polynsaturated fatty acids and prevention of cardiovascular disease - Eat fish or take fish oil supplement? Prog Cardiovasc Dis. 2009;52:95-114. 